\title{
ROBUST CONTROLLER FOR SUPERSONIC UNMANNED AERIAL VEHICLE
}

\author{
Vitalii BURNASHEV (D) *, Aleksandr ZBRUTSKY \\ Department of Aircraft Control Systems, National Technical University of Ukraine \\ "Igor Sikorsky Kyiv Polytechnic Institute", Kiev, Ukraine
}

Received 7 November 2018; accepted 29 April 2019

\begin{abstract}
The article is devoted to the synthesis of robust controllers of supersonic unmanned aerial vehicle motion parameters. During the flight, the velocity and altitude of the aircraft varies rapidly within wide limits. Therefore, the required quality of control on each trajectory is provided by a set of dynamic controllers with constant coefficients. The article substantiates the number of such controllers, researches the range of their efficiency. The obtained restrictions on the amplitude-frequency characteristics and weight functions are given. Transients are shown.
\end{abstract}

Keywords: supersonic unmanned aerial vehicle, robust controller, flight trajectory, control quality, transient, controller synthesis.

\section{Introduction}

The flight parameters of jet unmanned aerial vehicles (UAVs) in a short time can vary within very wide limits (S.-H. Kim, Y.-S. Kim, \& Song, 2004; Lebedev \& Chernobrovkin, 1973). In this case, there are significant parametric perturbations of the motion mathematical model, which do not allow the use of qualitative control laws with constant parameters. On the other hand, the use of adaptive controllers implies a large amount of computation, which reduces the reliability of the control system, and imposes strict requirements on the characteristics of the onboard computer (Zavalnaya \& Burnashev, 2015).

Recently, many researchers have been working in the field of UAV automatic flight control (Oktay, Çelik, \& Türkmen, 2018; Turkoglu \& Jafarov, 2007; Oktay, Konar, Onay, Aydin, \& Abdallah Mohamed, 2016; Oktay \& Çoban, 2017; Babar et al., 2013). Adaptive approach is considered in (Ablesimov \& Gonchar, 2013; Wang, Patel, Woolsey, Hovakimyan, \& Schmale, 2007; Fradkov \& Andrievsky, 2005). More researchers suggest using robust controllers (Jafar, Fasih Ur Rehman, Fazal Ur Rehman, \& Nisar, 2016; Lin, Zhang, \& Brandt, 1999; López, R. Dormido, S. Dormido, \& Gómez, 2015; Sobhani, 2007; Rui, Zhou, \& Yanhang, 2007).

For a supersonic UAV a balance between control quality and robustness on the one hand, as well as simplicity and reliability of the system on the other, can be found through the use of a small set of robust controllers capa- ble to operate in all sectors of possible flight paths. The reviewed literature and the results of previous researches allow us to hope for it (Bogoslavets, Burnashev, \& Ponomarenko, 2017; Kim et al., 2004).

We will consider the problem of synthesizing robust controllers of the supersonic UAV motion parameters and studying their efficiency in a wide range of variations in velocities and altitudes.

\section{Mathematical model of the control object}

The unmanned aerial vehicle is equipped with a solidfuel engine and aerodynamic controls. Each channel of translational motion automatic control of the considered UAV consists of the internal loop of the angular motion oscillations damping and the external loop of the linear acceleration control (Figure 1).

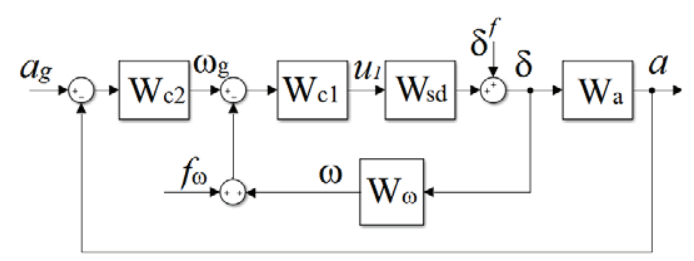

Figure 1. Block diagram of the control channel for the centre of mass acceleration

${ }^{*}$ Corresponding author. E-mail: vvvburnashev@gmail.com 
In Figure $1 W_{a}, W_{\omega}$ are the aircraft transfer functions for acceleration and angular velocity; $W_{c 1}, W_{c 2}$ are the aircraft transfer functions of the external and internal loop controllers; $\delta$ is the angle of rotation of the aerodynamic control surface; $f_{\omega}, \delta^{f}$ are disturbances; $a_{g}, \omega_{g}$ are reference signals; $u_{1}$ is the servo control signal. The servo transfer function $W_{s d}$ is a second-order unit with a time constant of $0.01 \mathrm{~s}$ and a pure time delay of $0.005 \mathrm{~s}$.

The same parameters of the control object transfer functions $W_{a}, W_{\omega}$ may take values that differ many times depending on the choice of the trajectory. In addition, they quickly change during the flight. For altitude of $9000 \mathrm{~m}$ and velocity of $568 \mathrm{~m} / \mathrm{s}$ :

$$
\begin{aligned}
& W_{a}=\frac{1.471 s^{2}+1.108 s+425.1}{0.01423 s^{2}+0.02025 s+1} ; \\
& W_{\omega}=\frac{0.8473 s+0.7478}{0.01423 s^{2}+0.02025 s+1},
\end{aligned}
$$

where $s$ is the Laplace variable. The denominator of transfer functions $W_{a}, W_{\omega} \mathrm{D}(\mathrm{s})=d_{2} s^{2}+d_{1} s+1$ depends on the position of the center of mass relatively to the pressure center:

$$
\begin{aligned}
& d_{2}=\frac{-m V^{2} I_{z}}{q S_{a} l\left(c_{n}^{\alpha}\left(x_{1}-x_{2}\right) m V^{2}+\operatorname{lm}_{z}^{w z}\left(q S_{a} c_{n}^{\alpha}+P\right)\right)} \\
& d_{1}=-\frac{V}{q S_{a} l} \cdot \frac{\left(I_{z} c_{n}^{\alpha}-l^{2} m_{z}^{w z} m\right) q S_{a}+P I_{z}}{c_{n}^{\alpha}\left(x_{1}-x_{2}\right) m V^{2}+l m_{z}^{w z}\left(q S_{a} c_{n}^{\alpha}+P\right)},
\end{aligned}
$$

where $m, I_{z}$ are the aircraft mass and moment of inertia; $V$ is a velocity; $q$ is a velocity head; $S_{a}, l$ are the characteristic area and length of the aircraft; $x_{1}, x_{2}$ are the positions of the center of mass and aerodynamic focus; $P$ is a thrust; $c_{n}^{\alpha}$ is the derivative of normal force on the angle of attack; $m_{z}^{w z}$ is the derivative of the coefficient of aerodynamic moment on the pitch angular velocity. Since the first few seconds of flight, the UAV has back centering $W_{a}$ and $W_{\omega}$ are unstable:

$$
\begin{aligned}
& W_{a}=\frac{9.337 s^{2}+11.3 s+3207}{0.1534 s^{2}+0.3628 s-1} ; \\
& W_{\omega}=\frac{9.068 s+10.25}{0.1534 s^{2}+0.3628 s-1} .
\end{aligned}
$$

\section{Synthesis of the controller at a given point of the flight trajectory}

The controller should provide a transient time of no more than $0.5 \mathrm{~s}$, an overshoot of up to $30 \%$, as well as firstorder astatism with satisfactory stability margins and limited control surface angular displacement. In addition, it should parry the disturbance $\delta^{f}$.

To satisfy all these requirements, as well as to provide the necessary insensibility with respect to parametric perturbations, the $H_{\infty}$ theory (Skogestad \& Postlethwaite, 2005) can be applied. At that, the synthesis should be carried out in two stages: at the first determine the transfer function of the controller for the internal loop, and at the second for the external one.
Quality criteria for the synthesis of the internal loop controller

$$
\left\|\begin{array}{ll}
W_{11} \Phi_{g e 1} & W_{11} \Phi_{f e 1} W_{13} \\
W_{12} \Phi_{g u 1} & W_{12} \Phi_{f u 1} W_{13}
\end{array}\right\|_{\infty} \leq 1
$$

where $\Phi_{g e 1}=\frac{\omega_{g}(s)-\omega(s)}{\omega_{g}(s)} ; \Phi_{g u 1}=\frac{\delta(s)}{\omega_{g}(s)} ; \Phi_{f u 1}=\frac{\delta(s)}{\delta^{f}(s)}$;

$\Phi_{f e 1}=\frac{\omega_{g}(s)-\omega(s)}{\delta^{f}(s)} ; W_{11}, W_{12}, W_{13}$ are weight functions.

Quality criteria for the synthesis of the external loop controller

$$
\left\|\begin{array}{ll}
W_{21} \Phi_{g e 2} & W_{21} \Phi_{f e 2} W_{23} \\
W_{22} \Phi_{g u 2} & W_{22} \Phi_{f u 2} W_{23}
\end{array}\right\|_{\infty} \leq 1
$$

where $\Phi_{g e 2}=\frac{a_{g}(s)-a(s)}{a_{g}(s)} ; \Phi_{g u 2}=\frac{\omega_{g}(s)}{a_{g}(s)} ; \Phi_{f u 2}=\frac{\omega_{g}(s)}{f_{\omega}(s)}$; $\Phi_{f e 2}=\frac{a_{g}(s)-a(s)}{f_{\omega}(s)} ; W_{21}, W_{22}, W_{23}$ are weight functions.

A search of $W_{c 1}, W_{c 2}$ that satisfies criteria (3), (4) was carried out using an algorithm based on linear matrix inequalities (Skogestad \& Postlethwaite, 2005). For object (1), a representation of the internal loop controller in the state space is obtained:

$$
\begin{aligned}
& \dot{X}=A X+B U ; \\
& Y=C X+D U,
\end{aligned}
$$

where $X$ is the state vector; $Y=u_{1}$ is the output value of the controller (control action); $U=\omega_{g}-\omega$ is a controller input value;

$A=\left[\begin{array}{ccccc}-2426 & -731.1 & 8 \cdot 10^{4} & 3.674 \cdot 10^{4} & 2.014 \cdot 10^{6} \\ -2159 & -821.1 & 3.743 \cdot 10^{4} & 1.719 \cdot 10^{4} & 9.422 \cdot 10^{5} \\ -0.07578 & -0.1243 & -17.07 & -7.904 & -268.4 \\ -0.003875 & -0.01565 & 6.111 & -0.8898 & -4.787 \\ -21.8 & -8.422 & -289.3 & -9.418 & -1.508 \cdot 10^{5}\end{array}\right] ;$

$B=\left[\begin{array}{c}-2.857 \cdot 10^{4} \\ -1.337 \cdot 10^{4} \\ 2.569 \\ 0.7528 \\ 0.8508\end{array}\right]$;

$C=\left[\begin{array}{lllll}2.936 & 0.9475 & -86.26 & -39.61 & -2171\end{array}\right] ; D=30.8$.

The quality criterion (3) is equal to 0.873028 .

At the stage of internal loop synthesis, the focus is on the suppression of disturbance $\delta^{f}$, robustness and stability margins. At that the following restrictions on the amplitude-frequency characteristics were used (Figure 2).

At the stage of the external loop synthesis, the main indicators of the transient process quality are provided. When choosing weight functions, it is also important and difficult to suppress oscillations in the angular velocity of the UAV in the frequency range of 15-40 rad/s (Figure 3). The level of disturbance suppression of the external loop 

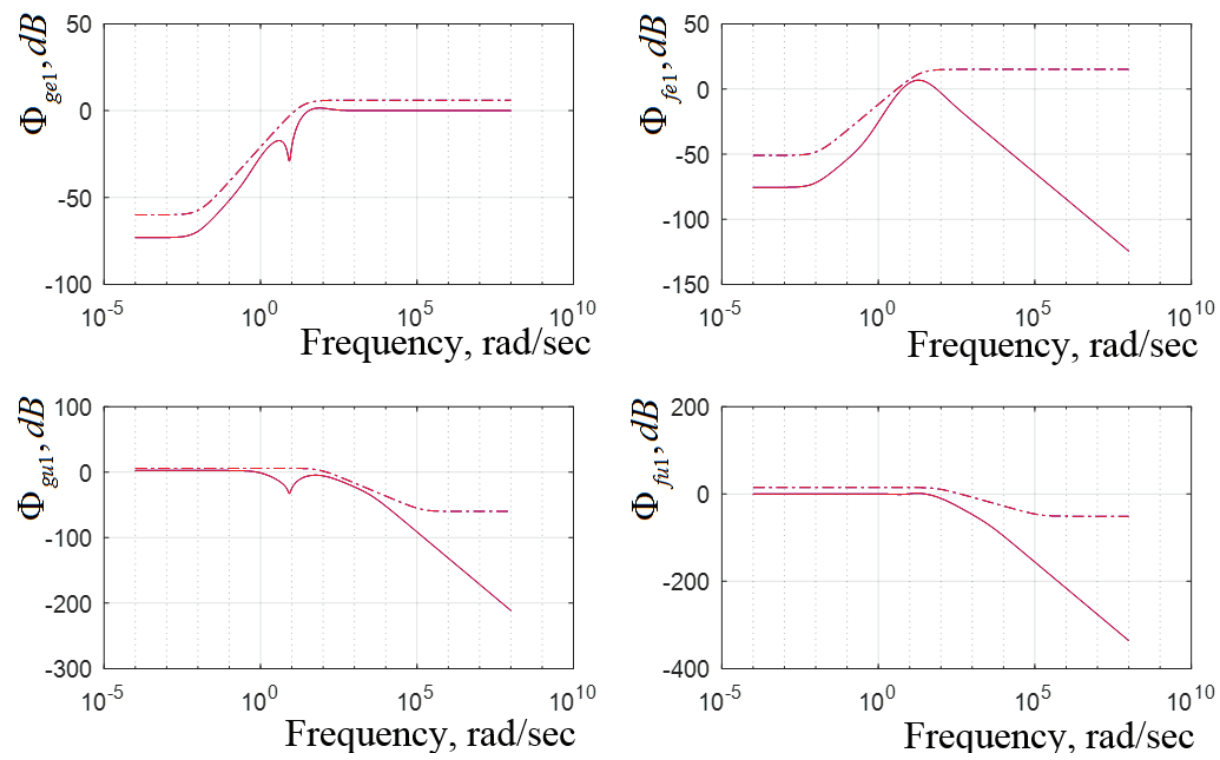

Figure 2. Bode diagrams of the internal closed loop with a controller
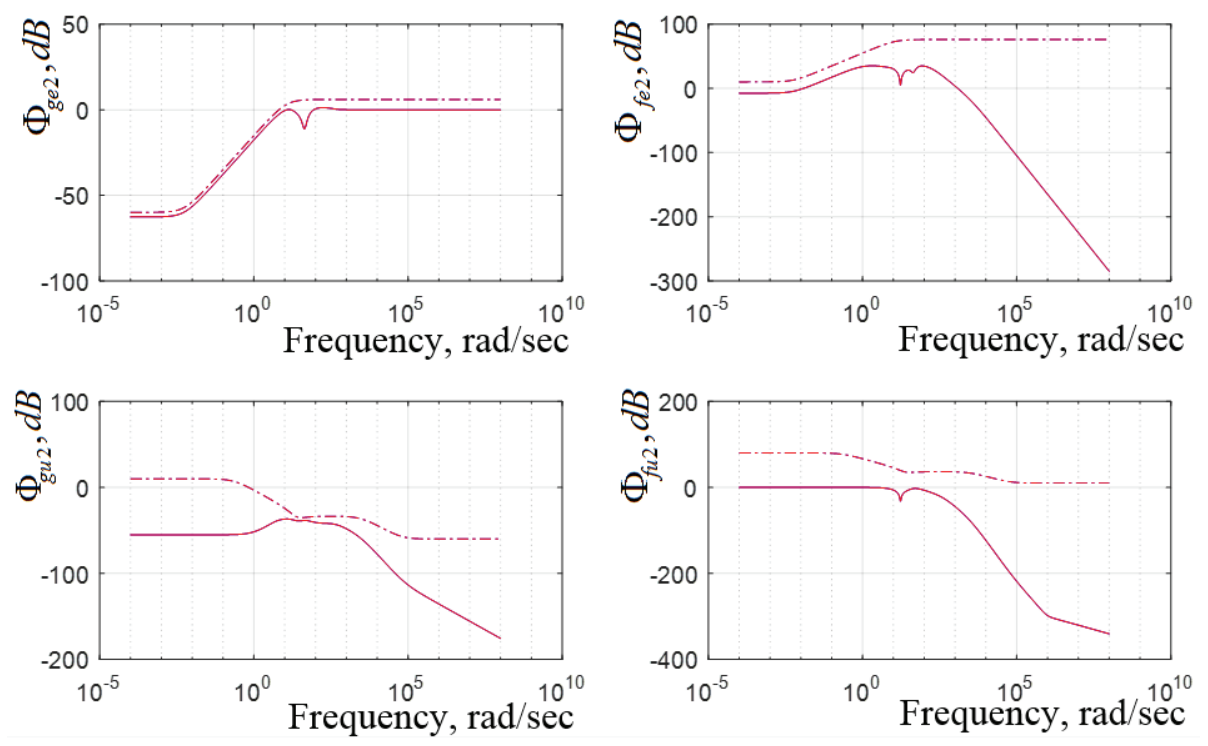

Figure 3. Bode diagrams of the external closed loop with a controller

$f_{\omega}$ imposes a limit on the angular velocity sensor. A gain of $35 \mathrm{~dB}$ for $\Phi_{f e 2}$ (Figure 3) is not significant if the onboard navigation problem is solved autonomously by inertial means. In the case of using an integrated navigation system, when inertial meters are not basic, the accuracy of the gyroscope used may be low (Zbrutsky, Malysheva, \& Burnashev, 2014; Rahmouni \& Malysheva, 2012).

The solid lines in Figures 2, 3 show logarithmic amplitude-frequency characteristics for transfer functions, and dash-dotted show corresponding restrictions. They correspond to weight functions:

$$
\begin{aligned}
& W_{21}=\frac{501.2 s+5644}{1000 s+5.644} \\
& W_{22}=\frac{948.7 s^{3}+2.87 \cdot 10^{6} s^{2}+5.76 \cdot 10^{7} s+1.28 \cdot 10^{7}}{0.95 s^{3}+6 \cdot 10^{4} s^{2}+1.75 \cdot 10^{6} s+4.05 \cdot 10^{7}} \\
& W_{23}=0.000316
\end{aligned}
$$

For the external loop, in the controller equations (5) $Y=\omega_{g} ; U=a_{g}-a$, and the order of the control object even without taking into account the weight functions (7), taking into account the order of $W_{c 1}(6)$, is equal to 10 . It 
is known that the order of the controller found with the help of $H_{\infty}$-theory is equal to the order of the generalized object (Skogestad \& Postlethwaite, 2005). After lowering the order was equal to 7 , and the parameters of the state equations (5) are:

$A=\left[\begin{array}{ccccccc}0.005781 & -0.08976 & 0.01456 & 0.1428 & -0.04378 & -0.008428 & 0.1455 \\ -0.08976 & -22.44 & 41.94 & 58.49 & -19.28 & -4.396 & 74.05 \\ -0.01456 & -41.94 & -0.6695 & -17.74 & 4.776 & 0.7342 & -13.04 \\ 0.1428 & 58.49 & 17.74 & -269.6 & 104.3 & 43.99 & -653.9 \\ -0.04378 & -19.28 & -4.776 & 104.3 & -43.37 & -32.02 & 399.3 \\ 0.008428 & 4.396 & 0.7342 & -43.99 & 32.02 & -3.332 & 72.74 \\ -0.1455 & -74.05 & -13.04 & 653.9 & -399.3 & 72.74 & -1707\end{array}\right]$

$B=\left[\begin{array}{c}-0.1172 \\ -0.9249 \\ -0.1457 \\ 1.453 \\ -0.4448 \\ 0.0854 \\ -1.475\end{array}\right] ;$

$C=\left[\begin{array}{lllllll}-0.1172 & -0.9249 & 0.1457 & 1.453 & -0.4448 & -0.0854 & 1.475\end{array}\right]$; $D=0$.

As a result of the synthesis, the quality criterion (4) reached the value of 0.899071 ; the stability margin in amplitude is $23.1 \mathrm{~dB}$, in phase is 84.4 . To obtain a model in the state space and parameters $A, B, C, D(5)$, (6) Matlab was used.

The transient process in the synthesized system for the nominal point (1) has no overshoot and ends in 0.323 seconds (Figure 4). In this case, the aerodynamic control surface is able to work out a step change in the master acceleration $a_{g}$ by more than $100 \mathrm{~m} / \mathrm{s}^{2}$ (Figure 5).

With increasing flight velocity at the altitude of $9000 \mathrm{~m}$, the transition time for the UAV with a controller (5), (6), (8)

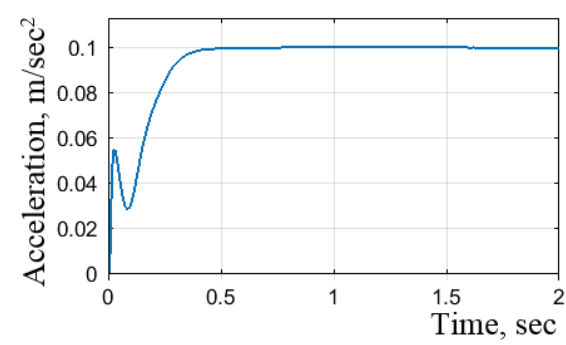

Figure 4. UAV reaction to the step master acceleration of $0.1 \mathrm{~m} / \mathrm{s}^{2}$

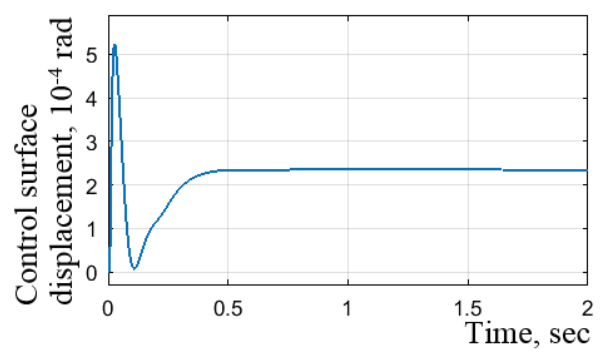

Figure 5. Rotation of the UAV aerodynamic control surface as a result of the step master acceleration of $0.1 \mathrm{~m} / \mathrm{s}^{2}$ decreases. However, this reduces the stability margins. For a reduced flight velocity, the transition time will be longer. The amplitude stability margin will also increase. The controller fully satisfies the requirements for control quality in the range of Mach numbers from $\mathrm{M}=1.39$ till $\mathrm{M}=4.3$. However, it remains operable even at $\mathrm{M}<1$, when the transition time becomes greater than $0.7 \mathrm{~s}$.

Controller calculations and simulation are carried out in the Matlab.

\section{Synthesis of controllers in the entire range of altitudes and flight speeds}

Thus, the controllers are calculated for all trajectories of the aircraft: for ascent, for horizontal flight in the height range of 300-14000 $\mathrm{m}$ and for descending.

It is most difficult to ensure the quality of control in the first seconds after launch (transfer functions (2)), as well as at high altitudes for low flight velocities due to the low efficiency of the controls. So, in the first five seconds of the flight, it is necessary to use 2 controllers, while the UAV control of the throughout the subsequent part of the 13-second climb trajectory is provided by one controller.

The stabilization of the horizontal flight trajectory in the range of Mach numbers $M=1-4.3$ for the selected altitude from the range of 300-9000 m was achieved with the help of two controllers. At altitudes of 10,000 and 14,000 , for this it was necessary to use the results of synthesis at three and four trajectory points, respectively. And for velocities above $M=1.2-2$ (depending on the height), the results of synthesis at one point are used.

For the descent stage, 1 or 2 controllers may be sufficient depending on the initial height and shape of the path. As a result, it was determined that for a fixed flight trajectory of the investigated supersonic UAV, it is necessary to synthesize a robust controller in 4-8 points.

If you need to use a set of different trajectories, the synthesis procedure turns out to be very time consuming. And its result depends on the successful selection of weight functions at each point. This research showed the effectiveness of using the same weight functions for the same values of velocity head. However, one controller cannot provide the required quality for a fixed velocity head in the entire range of altitudes and flight velocities.

\section{Conclusions}

The synthesized set of robust controllers provides the required quality of a supersonic UAV flight control from the moment of launch to the end of the flight in the entire range of permissible heights and velocities.

During the synthesis of the control channel internal loop at each point of the trajectory, the main attention should be paid to ensuring the stability margins and robustness, as well as suppressing the disturbance $\delta^{f}$. The external loop controller should provide a limited signal of a master angular velocity. It is also important to take into account the amplification of the angular velocity sensor error signal. 
To ensure the required quality of control of the investigated UAV on the entire flight trajectory from the moment of launch to the achievement of the goal, it is necessary to perform a synthesis procedure of robust controllers in 4-8 points. More often points should be taken on sites with low velocity head.

The efficiency of the synthesis of a control system that implements different trajectories can be improved if the same weight functions are used for the same values of the dynamic pressure.

The weight functions and limitations for the amplitude-frequency characteristics can be used as initial values in the synthesis of control systems of other similar aircraft.

In the future, it is intended to explore the feasibility of reducing the order of the synthesized controllers to simplify the system.

\section{References}

Ablesimov, O. K., \& Gonchar, A. Y. (2013). Adaptive control system for UAV with state observer. In IEEE 2nd International Conference Actual Problems of Unmanned Air Vehicles Developments Proceedings (APUAVD), Kiev, 15-17 October 2013 (pp. 203-205). IEEE. https://doi.org/10.1109/APUAVD.2013.6705326

Babar, M. Z., Ali, S. U., Shah, M. Z., Samar, R., Bhatti, A. I., \& Afzal, W. (2013). Robust control of UAVs using $\mathrm{H} \infty$ control paradigm. In IEEE 9th International Conference on Emerging Technologies (ICET), Islamabad, 9-10 December 2013 (pp. 1-5). IEEE. https://doi.org/10.1109/ICET.2013.6743506

Bogoslavets, R. O., Burnashev, V. V., \& Ponomarenko, K.V. (2017) Robastna systema keruvannya bezpilotnym litalnym aparatom. Mechanics of Gyroscopic Systems, 1(34), 14-21. (in Ukrainian). https://doi.org/10.20535/0203-3771342017122321

Fradkov, A., \& Andrievsky, B. (2005). Combined adaptive controller for UAV guidance. European Journal of Control, 11(1), 71-79. https://doi.org/10.3166/ejc.11.71-79

Jafar, A., Fasih Ur Rehman, S., Fazal Ur Rehman, S., \& Nisar, A. (2016). A Robust $\mathrm{H}$ infinity control law for unmanned aerial vehicle against atmospheric turbulence. In 2nd IEEE International Conference on Robotics and Artificial Intelligence (ICRAI), Islamabad 1-2 November 2016 (pp. 87-92). IEEE. https://doi.org/10.1109/ICRAI.2016.7791234

Lebedev, A. A., \& Chernobrovkin, L. S. (1973). Dinamika poleta bespilotnykh letatel'nykh apparatov. Uchebnoye posobiye dlya vuzov (Izdaniye 2-ye, pererabotannoye i dopolnennoye). Moskva: Mashinostroyeniye. (in Russian).

Lin, F., Zhang, W., \& Brandt, D. B. (1999). Robust hovering control of a PVTOL aircraft. IEEE Transactions on Control Systems Technology, 7(3), 343-351. https://doi.org/10.1109/87.761054

López, J., Dormido, R., Dormido, S., \& Gómez, J. P. (2015). A Robust $H \infty$ controller for an UAV flight control system. The Scientific World Journal, 2015, 11 p. https://doi.org/10.1155/2015/403236
Oktay, T., Çelik, H., \& Türkmen, I. (2018). Maximizing autonomous performance of fixed-wing unmanned aerial vehicle to reduce motion blur in taken images. Proceedings of the Institution of Mechanical Engineers Part I - Journal of Systems and Control Engineering, 232, 857-868. https://doi.org/10.1177/0959651818765027

Oktay, T., \& Çoban, S. (2017). Simultaneous longitudinal and lateral flight control systems design for both passive and active morphing TUAVs. Elektronika ir elektrotechnika, 23(5), 15-20. https://doi.org/10.5755/j01.eie.23.5.19238

Oktay, T., Konar, M., Onay, M., Aydin, M., \& Abdallah Mohamed, M. (2016). Simultaneous small UAV and autopilot system design. Aircraft Engineering and Aerospace Technology, 88(6), 818-834. https://doi.org/10.1108/AEAT-04-2015-0097

Rahmouni, M., \& Malysheva, J. (2012). An integrated aircraft navigation system with optical horizon sensor. Aviation, 16(4), 109-114. https://doi.org/10.3846/16487788.2012.753681

Rui, W., Zhou, Z., \& Yanhang, S. (2007). Robust landing control and simulation for flying wing UAV. In 2007 Chinese Control Conference, Hunan, 26-31 July 2007 (pp. 600-604). https://doi.org/10.1109/CHICC.2006.4346934

Kim, S.-H., Kim, Y.-S., \& Song, C. (2004). A robust adaptive nonlinear control approach to missile autopilot design. Control Engineering Practice, 12(2), 149-154. https://doi.org/10.1016/S0967-0661(03)00016-9

Skogestad, S., \& Postlethwaite, I. (2005). Multivariable feedback control: analysis and design (2nd ed.). New York: Wiley.

Sobhani, R. (2007). A nonlinear digital robust controller for UAV. In IEEE Aerospace Conference, Big Sky, MT, 3-10 March 2007 (pp. 1-6). https://doi.org/10.1109/AERO.2007.352758

Turkoglu, K., \& Jafarov, E. M. (2007). Augmented optimal LQR control system design for the longitudinal flight dynamics of an UAV: Inner and outer loop concets. In 9th WSEAS International Conference on Automatic Control, Modeling \& Simulation, Istanbul, 27-29 May 2007 (pp. 100-105).

Wang, J., Patel, V., Woolsey, C. A., Hovakimyan, N., \& Schmale, D. (2007). L1 adaptive control of a UAV for aerobiological sampling. In American Control Conference, New York, NY, 9-13 July 2007 (pp. 4660-4665). https://doi.org/10.1109/ACC.2007.4283121

Zavalnaya, O. S., \& Burnashev, V. V. (2015). Upravleniye dvizheniyem bespilotnogo letatel'nogo apparata $\mathrm{v}$ usloviyakh neopredelennosti. Mekhanika giroskopicheskikh system, (29), 15-23. (in Russian). https://doi.org/10.20535/0203-377129201562696

Zbrutsky, A. V., Malysheva, J. A., \& Burnashev, V. V. (2014). Navigation and orientation system with optical horizon sensor for mini UAV. IEEE 3rd International Conference on Methods and Systems of Navigation and Motion Control, Kiev, 14-17 October 2014 (pp. 15-17). IEEE. https://doi.org/10.1109/MSNMC.2014.6979717 